\title{
Experimental Study on Hygrothermal Deformation of External Thermal Insulation Cladding Systems with Glazed Hollow Bead
}

\author{
Houren Xiong, ${ }^{1,2}$ Jinming $X u,{ }^{1}$ Yuanzhen Liu, ${ }^{3}$ and Shimeng Wang ${ }^{3}$ \\ ${ }^{1}$ Department of Civil Engineering, Shanghai University, Shanghai 200444, China \\ ${ }^{2}$ Building Energy Efficiency Technology Laboratory, Jiaxing University, Jiaxing 314001, China \\ ${ }^{3}$ College of Architecture and Civil Engineering, Taiyuan University of Technology, Taiyuan 030024, China \\ Correspondence should be addressed to Houren Xiong; 104072005@163.com
}

Received 30 July 2016; Accepted 16 October 2016

Academic Editor: Doo-Yeol Yoo

Copyright (C) 2016 Houren Xiong et al. This is an open access article distributed under the Creative Commons Attribution License, which permits unrestricted use, distribution, and reproduction in any medium, provided the original work is properly cited.

\begin{abstract}
This research analyzes the thermal and strain behavior of external thermal insulation cladding systems (ETICS) with Glazed Hollow Beads (GHB) thermal insulation mortar under hygrothermal cycles weather test in order to measure its durability under extreme weather (i.e., sunlight and rain). Thermometers and strain gauges are placed into different wall layers to gather thermal and strain data and another instrument measures the crack dimensions after every 4 cycles. The results showed that the finishing coat shrank at early stage (elastic deformation) and then the finishing coat tends to expand and become damaged at later stage (plastic deformation). The deformation of insulation layer is similar to that of the finishing coat but its variation amplitude is smaller. Deformation of substrate expanded with heat and contracted with cold due to the small temperature variation. The length and width of cracks on the finishing coat grew as the experiment progressed but with a decreasing growth rate and the cracks stopped growing around 70 cycles.
\end{abstract}

\section{Introduction}

Due to the rapid economic development, there has been a constant increase in the building energy consumption in China. According to the relevant statistics, the building energy consumption accounts for about $30 \%$ of the total energy consumption of the society at large [1]. As for a building, according to the statistics, the external walls of a building, or the barriers between the internal and the external parts, roughly account for $45 \%$ of the total building external area. The energy dissipated through the walls from the structure enclosure accounts for more than $60 \%$ of the energy loss of the entire building [2]. Accordingly, the most effective way of reducing the energy dissipation through the walls is to improve the thermal insulation of its external walls.

Many approaches have been made referred to the thermal insulation systems for the peripheral structures of buildings. Dozens of thermal insulation systems for the external walls of buildings were developed [2-4]. Specifically, by using an insulating layer made of porous inorganic materials, the external thermal insulation composite systems with Glazed Hollow Bead thermal insulation mortar (ETICS GHB) are characterized by the high thermal insulation and fireproof performances. The ETICS GHB have been widely applied in China and many researchers investigated this system in the preparation and molding [5-7], thermal insulation property and shrinkage deformation [8-10], mechanical property [11, 12], and antifrost property [13]. However, only the functional analyses were focused on the GHB mortar or concrete and single material was concerned in most approaches. Little was taken accounted for the ETICS GHB, a system made of laminated composite materials, from their hygrothermal properties [10], especially from durability in a hygrothermal environment.

In practice, due to the heat blocking action of the insulating layer, heat is usually stored in the finishing coat of the ETICS. For instance, in the summer, the temperature of the ETICS finishing coat may reach $70^{\circ} \mathrm{C}$. On the other hand, if a rainstorm occurs after several sunny days, the surface temperature may suddenly drop to $50^{\circ} \mathrm{C}$ [14]. This 
temperature change caused by sunshine and rain will reduce the strength and the thermal insulation effect of the materials in the ETICS. The temperature change may also cause hygrothermal deformation of the materials and thereafter result in the damage in the structure (such as cracking of the insulating layer, separation of the insulating layer from the base, and falloff of the finishing coat). These damage affect the normal service of ETICS [15-17]. For this reason, a high temperature-rain simulation test on ETICS, in the current study, was conducted in order to determine the hygrothermal deformation and hygrothermal mechanical properties of the finishing coat material. The test may provide vital scientific and engineering information both in evaluating the reliability and service life of the ETICS and in formulating guidelines for a safe ETICS design.

Many approaches have been made on the hygrothermal deformation of ETICS, Zirkelbach et al. [18] conducted a five-year hygrothermal coupling analysis on the mineral wool ETICS in three European countries with various climatic conditions. He compared the temperature and humidity data from southern Portugal and northern Finland with those measured in central Germany. Zhang et al. [19] used a finite difference method to analyze the temperature stresses in the internal and external thermal insulation walls. Collina and Lignola [20] combined stress-strain to analyze the influence of various stresses (such as shear stress and thermal stress) on the durability of ETICS. Balocco et al. [21] used the finite element software ANSYS to conduct a thermal fatigue study on ETICS. Passa et al. [22] conducted the thermal strain test on various structural layers of EPS thermal insulation systems in oven heating and analyzed the influence of external temperature on the deformation of various structural layers. Yiu et al. [23] used a simple equipment to conduct the hygrothermal cycle test on the small-scale wall test specimens pasted with strain gauges in order to obtain the deformation curves of the concrete, rendering, and tiles. Griciute and Bliudzius [24] conducted the contrast tests in the indoor and natural ageing on ETICS made of three finishing coat materials (i.e., acrylic, silicone, and silicate). They analyzed the change features in the microstructures, ingredients, and water contents of these materials. Daniotti et al. [25] used six cameras to monitor the finishing coat of the ETICS in the accelerated ageing test and recorded the degradation failure phenomena at different deformation stages.

However, the degradation features of various structural layers in the ETICS GHB under hygrothermal cycle are of great importance; few of the existing studies, as we know, focused on these features. In this study, referring to the test method as described in the European standard ETAG 004 [26], a high temperature-rain periodic test was conducted on large-scale ETICS GHB. The temperature sensors and strain gauges were embedded in various structural layers to measure the temperature and strain of various structural layers under hygrothermal cycles. The changes in temperature and strain in various structural layers of the ETICS GHB were also examined. The degradation characteristics of the finishing coat with the number of cycles were thereafter quantitatively investigated.
TABle 1: Properties of GHB.

\begin{tabular}{lc}
\hline Properties & Values \\
\hline Particle size $(\mathrm{mm})$ & $0.5-1.5$ \\
Cylindrical compress strength $(\mathrm{kPa})$ & $\geq 150$ \\
Bulk density $\left(\mathrm{kg} / \mathrm{m}^{3}\right)$ & $80-130$ \\
Thermal conductivity $(\mathrm{W} /(\mathrm{m} \mathrm{K}))$ & $0.032-0.045$ \\
Surface vitrified close cell content $(\%)$ & $\geq 95$ \\
Volatile water absorption $(\%)$ & $20-50$ \\
Volume floating rate $(\%)$ & $\geq 98$ \\
\hline
\end{tabular}

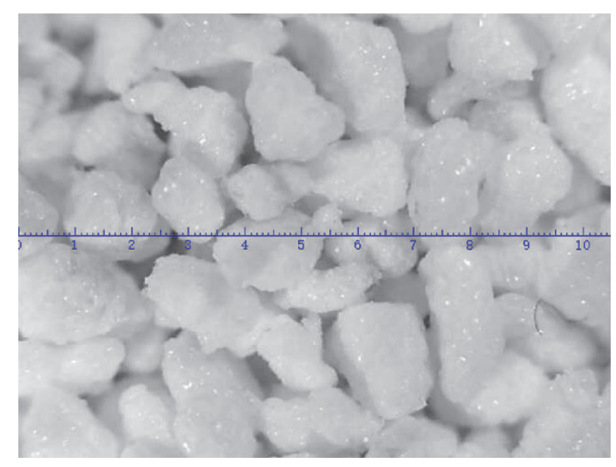

Figure 1: Glazed Hollow Bead dimension (mm).

\section{Materials and Experimental Procedure}

2.1. Glazed Hollow Bead. Glazed Hollow Beads were produced by Henan Xinyang Yongxin Perlite Plant (China). The GHB particle sizes dimensions are shown in Figure 1. The properties of GHB particles are shown in Table 1.

2.2. Preparation of Rig for Test. The substrate of the rig was prepared in accordance with the dimensions in [26], which is $3.0 \mathrm{~m}$ (width) $\times 2.0 \mathrm{~m}$ (height) concrete wall with $0.6 \mathrm{~mm}$ (height) $\times 0.4 \mathrm{~m}$ (width) aluminum alloy window (see Figure 2). The structure of the rig from inside to outside is formed by substrate, bonding layer, insulation layer, reinforced base coat, and finishing coat (see Figure 3). The thermal parameters of the rig wall are detailed in Table 2.

The preparation procedure was described as follows. The substrate base was first cleaned and moisturized. The adhesion agent was then brushed. After drying the adhesion agent for at least $24 \mathrm{~h}$, two layers of the GHB thermal insulation mortar were applied. The second layer was applied after setting the initial conditions of the system and completing the first layer. After curing the insulating layer in three days, two layers of the anticrack mortar were applied on and pressed in the alkali-resistant glass fiber mesh between the first and second layers which were set. Then, the anticrack layer was cured for three days and the flexible putty was applied twice after being cured for at least one day. The external wall waterproof priming coat was sprayed and the top layer was finished. Furthermore, the system was cured at laboratory for 28 days. After completing the curing stage, the weathering test was conducted. To monitor the distribution of the temperature at different positions and structural layers along the horizontal 


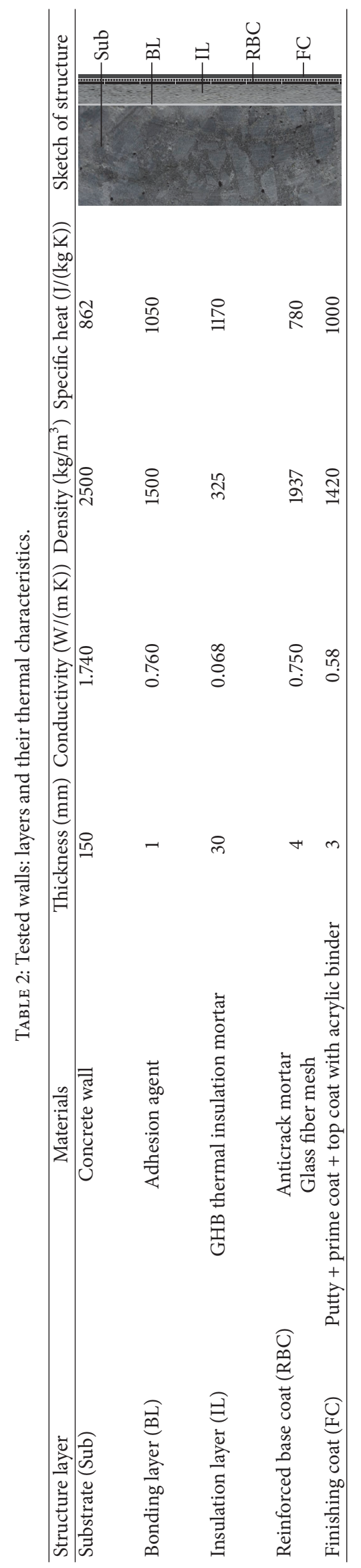




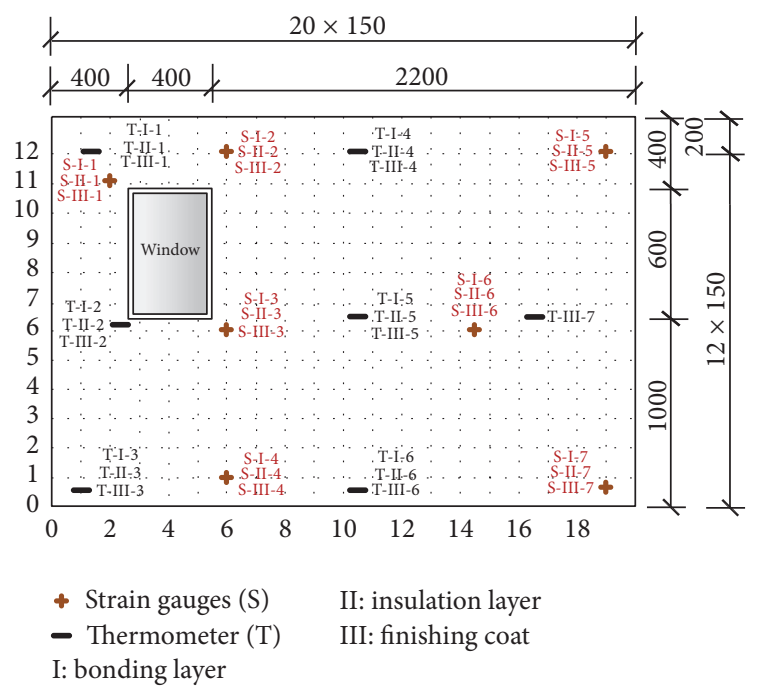

FIGURE 2: Schematic graph of measuring points (mm).

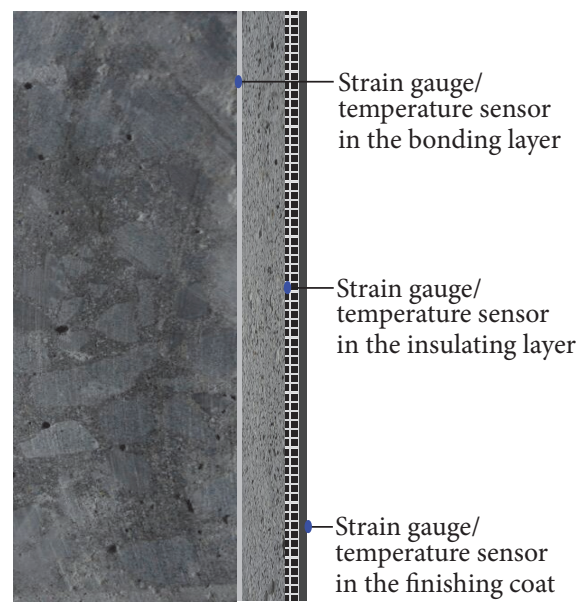

FIgURE 3: Strain gauges and temperature sensors profiles in the vertical section.

and vertical directions of the test wall surface, the strain gauges and temperature sensors in preparing ETICS GHB should be installed at the same positions as the concrete base, the insulating layer (outer surface), and the finishing coat. Seven strain gauges and six temperature sensors were installed in each layer (see Figures 2-4).

2.3. Test Apparatus. (1) The weathering test chamber can simulate the effect of hot and rainy summer weather with evaporators and fans on the ceiling and spraying system set up by the two sides of the chamber near the testing rigs (see Figure 5). Altogether the test chamber can reproduce the damage to ETICS in a few weeks that occur over many years outdoors, where the range of simulated temperature is from $-25^{\circ} \mathrm{C}$ to $100^{\circ} \mathrm{C}$ and the range of simulated rainwater temperature is $10^{\circ} \mathrm{C}$ to $20^{\circ} \mathrm{C}$ with the precision of $\pm 1.0^{\circ} \mathrm{C}$.

(2) INV $2312 \mathrm{~N}$ wireless bus static strain test system: the system is characterized by high sampling rate and high stability with a temperature drift less than $1 \mu \varepsilon /{ }^{\circ} \mathrm{C}$, a time drift less than $3 \mu \varepsilon / 4 \mathrm{~h}$, and the measurement precision of $\pm 0.3 \%$ $\mathrm{FS} \pm 2 \mu \varepsilon$.

(3) KON-FK (N) crack width detector: the detector may automatically and quickly record the width of a crack with a precision of $0.01 \mathrm{~mm}$.

(4) GM eight-channel temperature acquisition system: in connecting to the DS18B20 waterproof copper sensor probe, the system may simultaneously record temperature signals at 32 points within the temperature from $-55^{\circ} \mathrm{C}$ to $125^{\circ} \mathrm{C}$ and the resolution of $0.0625^{\circ} \mathrm{C}$.

(5) Scanning electron microscopy (SEM) micrographs of the top coat and GHB mortar were obtained, respectively, using the types of SU-1510 and JSM-6700 (Hitachi, Japan) at various cycles.

(6) KFG/KFW-5-120-D16-11L1M2S strain gauge: the biaxial overlapping configuration was used in the strain gauge in substrate combining with polyimide resin. The strain temperature drift in this arrangement may show by itself without connecting to a compensating plate. It is noted that the KFG series strain gauges were mainly laid out in the internal structures of the ETICS to make high waterproof and moisture-resistant performance. The series of strain gauges in KFW were mainly laid on the outdoor surface of the ETICS, even in the underwater or rainy environments. Table 3 shows the performance indexes of the strain gauges.

2.4. Artificial Weathering Tests. The cured ETICS GHB test specimens were placed inside the large-scale weathering test chamber. The strain gauges and temperature sensors should be properly connected Figure 6 shows the assembled test specimens. During a hygrothermal cycle test, the temperature range of hygrothermal cycle was set from $15^{\circ} \mathrm{C}$ to $70^{\circ} \mathrm{C}$, and the number of cycles was set at 80 with each cycle lasting for $6 \mathrm{~h}$. The heating process consists of raising the air temperature to $70^{\circ} \mathrm{C}$ in approximately 60 minutes and then maintaining the temperature at $70( \pm 5)^{\circ} \mathrm{C}$ for 120 minutes. The rain process consists of spraying water continuously for 60 minutes and then resting for 120 minutes. Both strain and temperature were recorded at an interval of $10 \mathrm{~min}$. A shutdown surface observation of the test wall was carried out at an interval of once in every four cycles to monitor the effect exerted by the thermal fatigue damage (i.e., crack, detachment, and swell). In order to quantitatively compare the surface damage results of the test specimen after different number of cycles, the surface of the test specimen was subdivided by a grid spacing of $15 \mathrm{~cm}$ (i.e., 20 grids in the horizontal direction and 13 grids in the vertical direction), as shown in Figure 2.

\section{Results and Analysis}

3.1. Temperature Field. To analyze the effect of temperature changes on various structural layers, it is necessary to determine the temperature features in various layers in the weathering test chamber. Taking 80 cycles in the hygrothermal conditions as an example, the data recorded at the fifth cycle were selected to examine the local change features in temperature at each point. Figure 7 (a) shows the temperature changing curves at the measuring points $\mathrm{T}$ I/II/III-4, T-I/II/III-5, and T-I/II/III- 6 on the wall surface in 


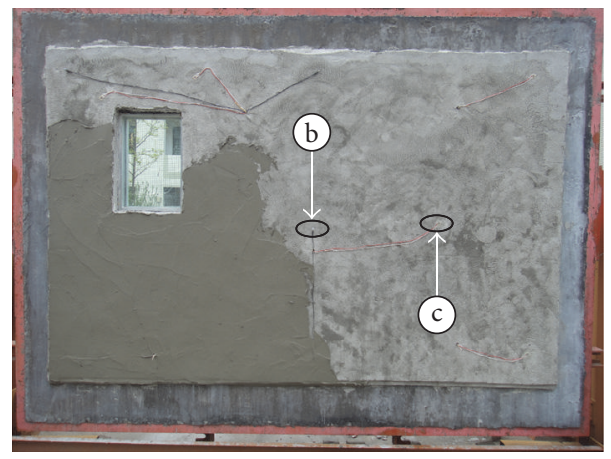

(a)

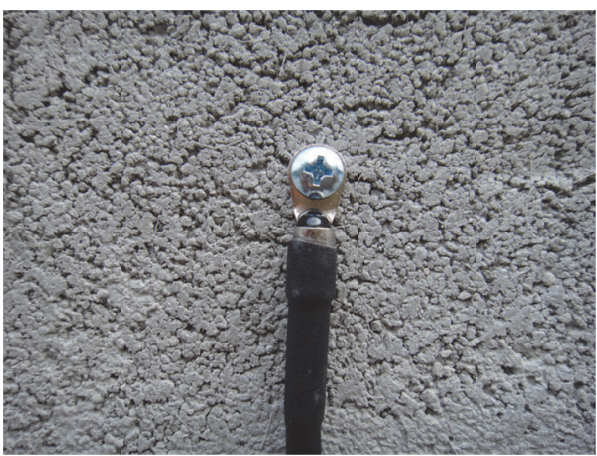

(b)

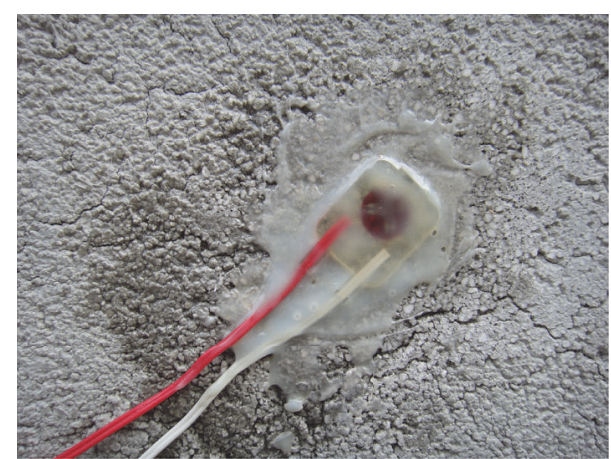

(c)

FIGURE 4: (a) The rig wall during construction phase and instrumented with temperature sensors and strain gauges between GHB mortar and reinforced base coat. (b) Temperature sensor. (c) Strain gauge.

TABle 3: Performance indexes of KFG/KFW.

\begin{tabular}{lcccr}
\hline Series & $\begin{array}{c}\text { Self-compensating } \\
\text { temperature range } /{ }^{\circ} \mathrm{C}\end{array}$ & $\begin{array}{c}\text { Self-compensating expansion } \\
\text { coefficient } / 10^{-6} /{ }^{\circ} \mathrm{C}\end{array}$ & Strain limit $/ \%$ & Fatigue life/number of times \\
\hline KFG & $10-100$ & 11.0 & 5.0 & $1.2 \times 10^{7}$ \\
KFW & $0-80$ & 10.8 & 2.8 & $3.0 \times 10^{4}$ \\
\hline
\end{tabular}

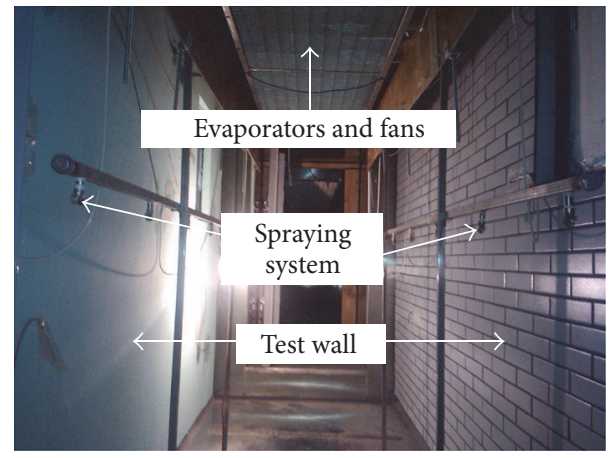

FIgURE 5: The weathering test chamber.

the vertical direction. Figure 7(b) shows the related curves at the measuring points T-I/II/III-2, T-I/II/III-5, and T-III7 on the wall surface in the horizontal direction. Figure 8 shows the variations in temperature at the measuring points T-I/II/III-1, T-I/II/III-2, T-I/II/III-5, and T-I/II/III-6 along the wall thickness direction.
(1) As shown in Figure 7, the temperature changing trend at different measuring points on the surfaces of the finishing coat and the insulating layer are similar and have a shape of a rectangular wave. However, the changing trend on the surface of the bonding layer has a shape of a triangular wave. The results imply that the GHB insulating material has an excellent thermal insulation effect in reducing the temperature transferred from the external temperature on the substrate wall; the temperature change rate of the bonding layer would slow down during the rising phase and raining phases and improve the indoor thermal comfort.

(2) As shown in Figure 7(a), the test chamber caused a progressively top-down decline in the temperature of the finishing coat, insulating layer, and bonding layer along the vertical direction of the wall surface. In this case, the largest temperature differences are among the upper and lower parts (i.e., $30^{\circ} \mathrm{C}$ for the finishing coat, $26^{\circ} \mathrm{C}$ for the insulating layer, and $12^{\circ} \mathrm{C}$ for the bonding layer). These temperature differences 


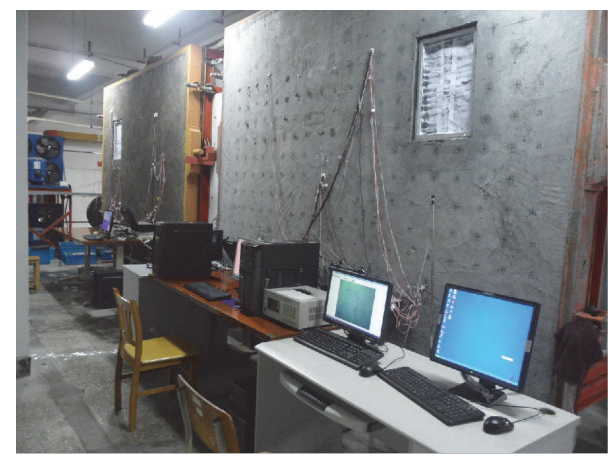

Figure 6: Data acquisition system of temperature and strain.

resulted in the deformation on the wall surface along the vertical direction and of the cracks along the horizontal direction. Figure 7(b) displays the temperature difference between the bonding layers and insulating layer is only about $1^{\circ} \mathrm{C}$ along the horizontal direction of the wall surface. Furthermore, the fluctuations at the measuring point T-III-7 of the finishing coat are more significant than those at the other points in the middle part, indicating that there is an unbalance in the local temperature in the test chamber.

(3) As shown in Figure 8, the maximum temperature differences between the upper points T-I-1 and TIII-1, the middle points T-I-2 and T-III-2 near the window, the middle points T-I-5 and T-III-5 near the center, and the lower points T-I-6 and T-III- 6 were $30.9^{\circ} \mathrm{C}$ at $60 \mathrm{~min}, 22^{\circ} \mathrm{C}$ at $120 \mathrm{~min}, 22^{\circ} \mathrm{C}$ at $120 \mathrm{~min}$, and $17.3^{\circ} \mathrm{C}$ at $180 \mathrm{~min}$, respectively. These results indicate that the surface temperatures at various points were affected by the local positions along the wall thickness direction. However, the differences in the temperatures from the top to lower parts are smaller with the largest one happening later.

3.2. Strain Field. In the test, the data recorded by the strain gauges are the total strain in each structural layer of the wall. The data in a total of 80 hygrothermal cycles were analyzed here. For the purpose of comparison, the measured temperatures near each measuring point, the strain-time-temperature relationship curves of the finishing coat, insulating layer, and bonding layer at different positions were depicted in Figures 9,10 , and 11 .

(1) As shown in Figure 9, for each period at the temperature rising and maintaining phases, the strain of the finishing coat changes synchronously with the temperature in the external layer. This indicates that the material of the finishing coat tended to expand with heat and to contract with cold surroundings at these two phases. At the raining phase, the temperature and strain of the finishing coat drop abruptly with a slight lag in the later curve (see Figures 9(b), $9(\mathrm{~d})$, and 9(f)). At the resting phase, the temperature of the finishing coat continues to fall at a slower rate. On the other hand, the strain would increase followed by an initial decrease as the temperature reaches that at the rising phase in the next period. These results are consistent with those obtained by Yiu et al. [23]. Therefore, the increase in strain during the resting phase may be caused by the hygroscopic expansion of the finishing coat material. For the entire cycle process, the maximum vertical and horizontal strains at the upper point $S$ III- 1 and the lower point S-III- 4 on the surface of the finishing coat are $9469 \mu \varepsilon$ and $1752 \mu \varepsilon$ at $N=80,1379 \mu \varepsilon$ at $N=78$, and $682 \mu \varepsilon$ at $N=5$, respectively ( $N$ stands for the hygrothermal cycle). However, the vertical and horizontal strains at the middle point S-III-6 rapidly drop to failure at $N=60$ and at $N=70$, respectively. These results indicate that the thermal deformation of the wall surface caused by the temperature difference in the vertical direction is two to four times of the deformation in the horizontal direction; in the finishing coat of the large-scale ETICS, the temperature gradient generated by the heat blocking action of the insulating layer results in an inconsistent overall hygrothermal deformation in different directions. These deformation gradients would accelerate the cracking of the finishing coat material and thereby shorten the durability of the material, as verified in Figures 15 and 16.

The finishing coat shrinks at early stage and expands after a number of cycles. The reason is that the micropores on the surface of the finishing coat are gradually blocked by the carbonized crystals at early time while the macropores may be generated between the crystals regions under the cycle load [24]. Figure 12 shows the scans electronic microscopy of the top parts of the finishing coat, respectively, before and after the test. The macropore structures appeared between the crystals in Figure 12(b). These pores resulted from the waterloss and shrinkage of the finishing coat. In the late stage of the 20th cycle, there is insignificant change in the structural porosity of the finishing coating material. As a consequence, the expansion with heat and the contraction with cold occurred in most positions, especially as in the maintaining phases. At this stage, an irreversible temperature-dependent creep deformation in the finishing coating material might be generated and accumulated with the cyclic temperature fluctuations. The continuous expansion would cause the coating material to split.

(2) Figures 9 and 10 show the results of the strains on the surfaces of the finishing coat and insulating layer. The change trends in these two figures are basically similar to each other, implying that the strain in the insulating layer may effectively illustrate the deformation of the insulating layer. However, the measured strain in the insulating layer is much smaller than that in the finishing coat due to the less influences of the external temperature and humidity on the GHB material of the insulating layer. From Figures 9 and 10, it can be also seen that most of the drying-shrinkage deformation occurred in the early stage and some of the thermally expansion deformation occurred at the later stage. During the hygrothermal cycle, the maximum/minimum vertical and horizontal strains were $495 /-962 \mu \varepsilon$ and $1072 /-188 \mu \varepsilon$, respectively. As shown in Figure 11, the strain in the bonding layer decreases abruptly due to the protection effect of the insulating material. None of the deformation exceeds the elastic limit in the concrete substrate regions. Hence, the safety is guaranteed for the internal concrete enclosure structure; the service life of the concrete might be lengthened. The maximum/minimum 


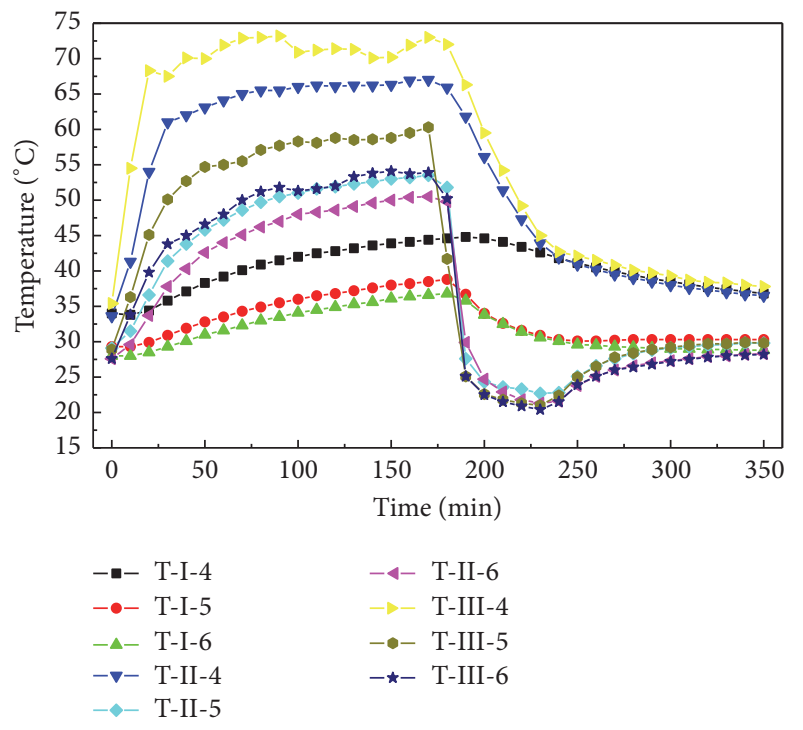

(a) Along the vertical direction of wall surface

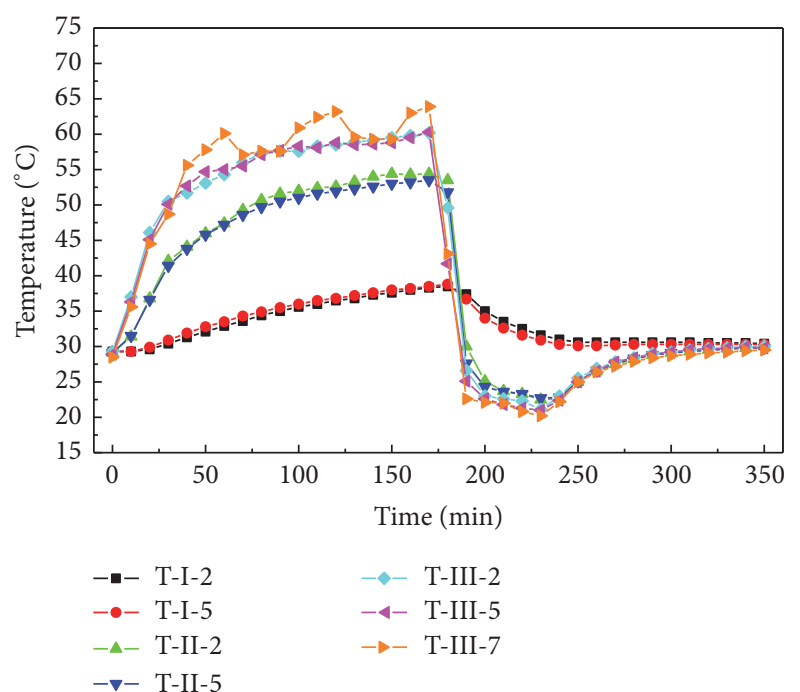

(b) Along the horizontal direction of wall surface

FIGURE 7: Temperature changing curves at various measuring points.

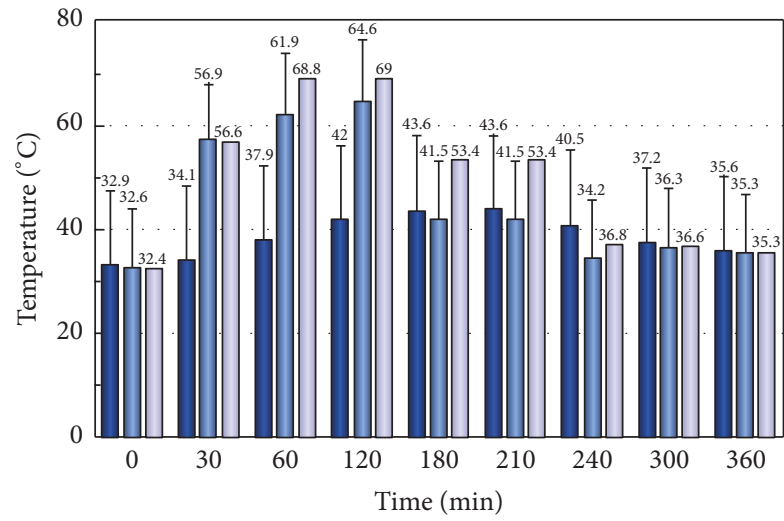

T-I-1

T-II-1

T-III-1

(a) $\mathrm{T}-\mathrm{I} / \mathrm{II} / \mathrm{III}-1$

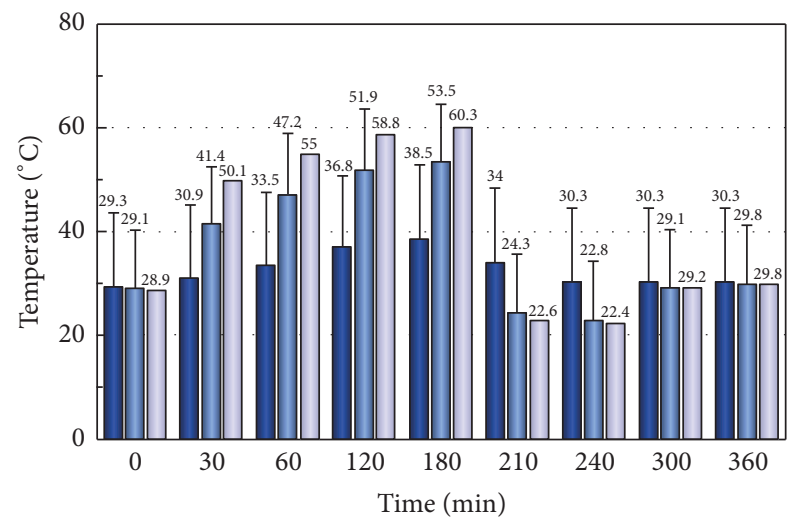

T-I-5

T-II-5

$\square$ T-III-5

(c) $\mathrm{T}-\mathrm{I} / \mathrm{II} / \mathrm{III}-5$

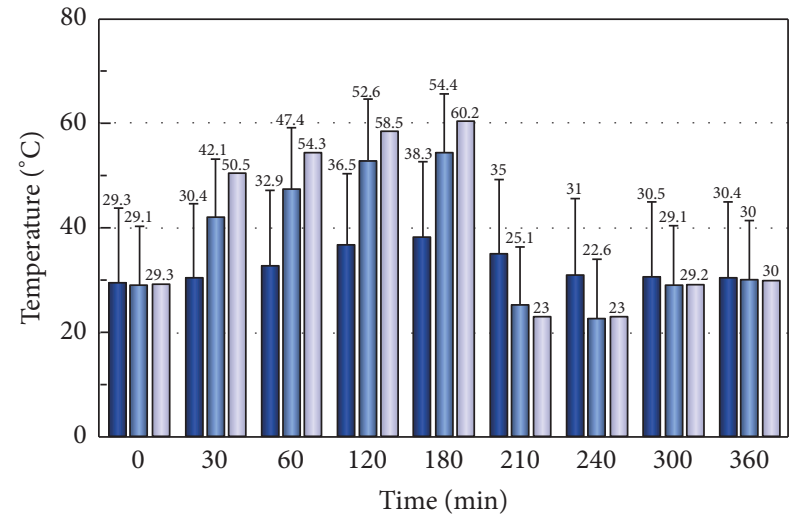

T-I-2

T-II-2

T-III-2

(b) T-I/II/III-2

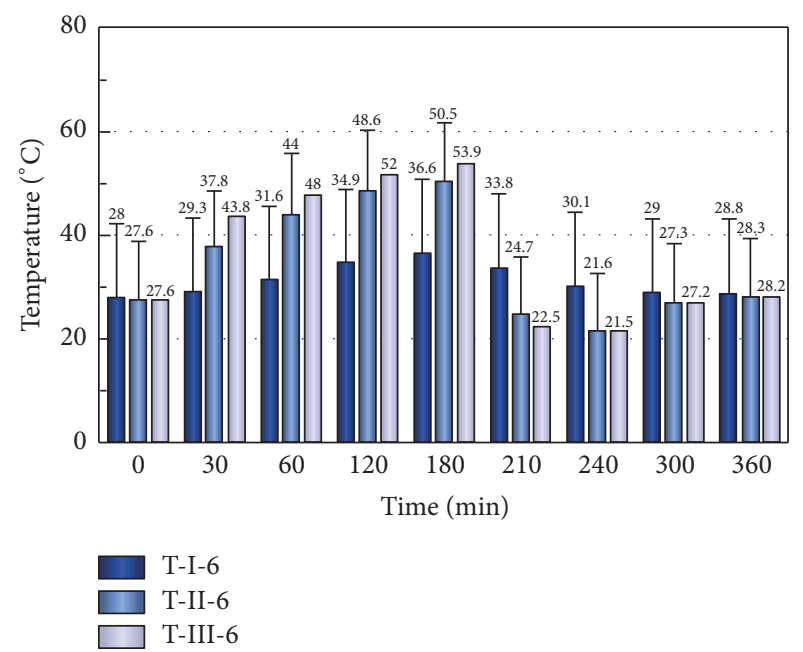

(d) $\mathrm{T}-\mathrm{I} / \mathrm{II} / \mathrm{III}-6$

FIGURE 8: Temperatures at various instants for different measuring points along the direction of wall thickness. 

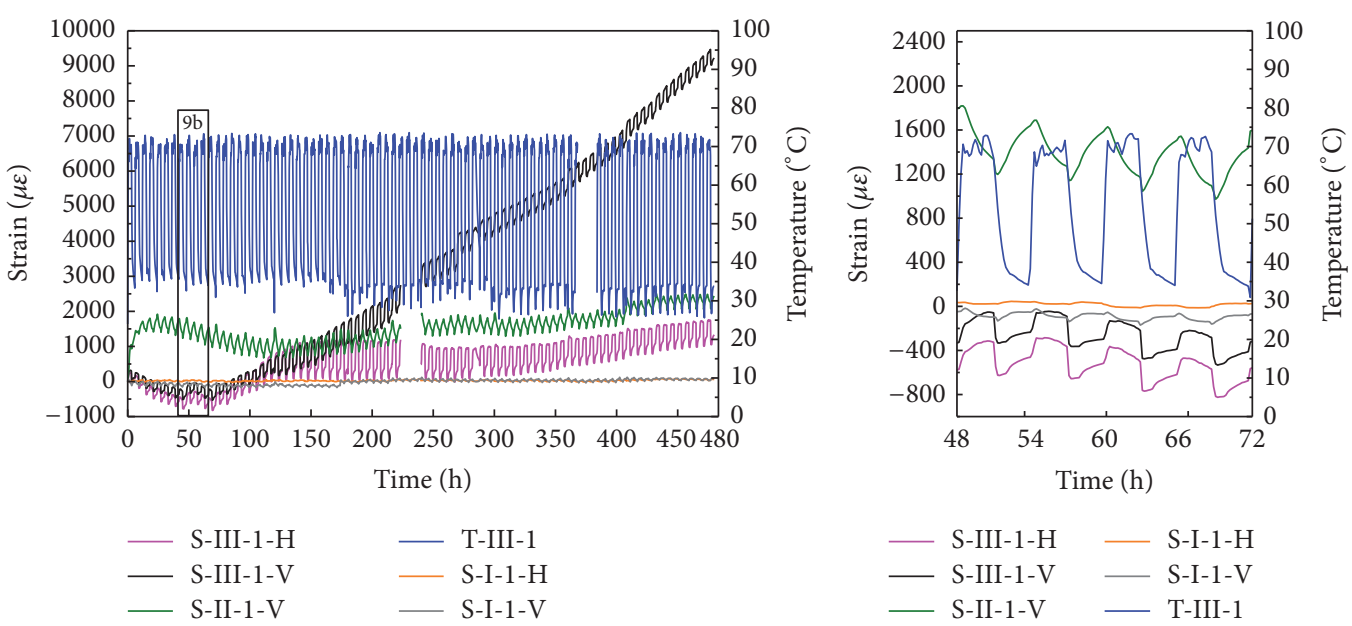

(a) In upper part
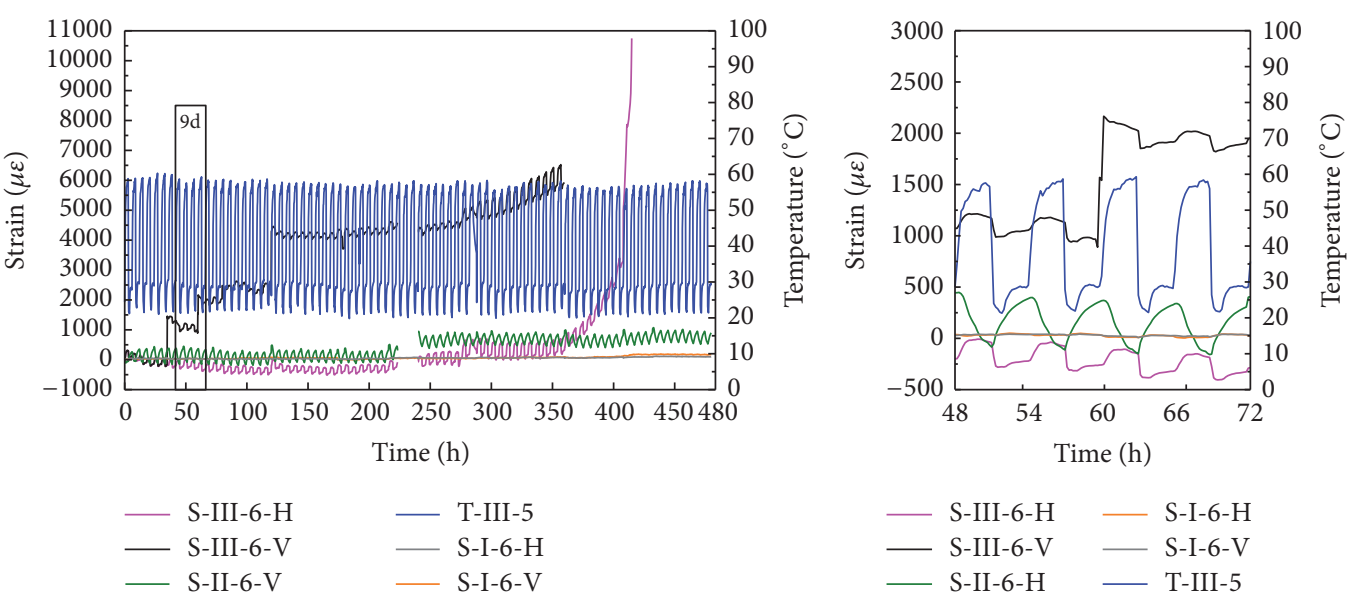

(c) In middle part
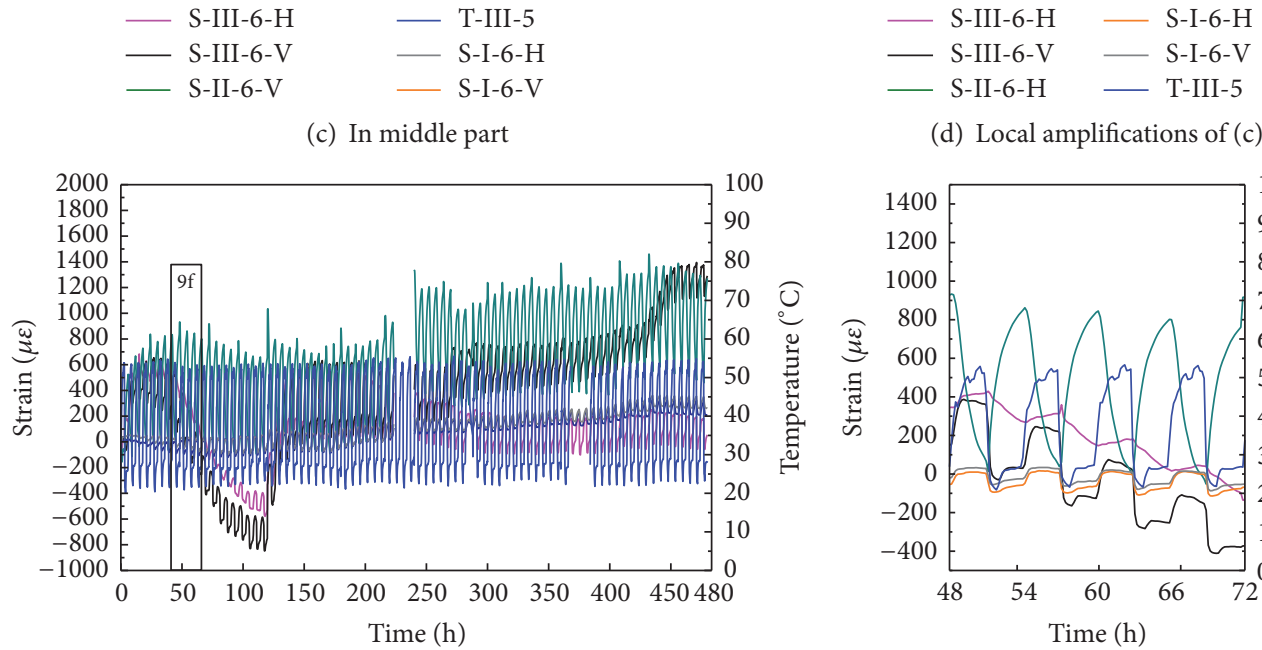

(d) Local amplifications of (c)
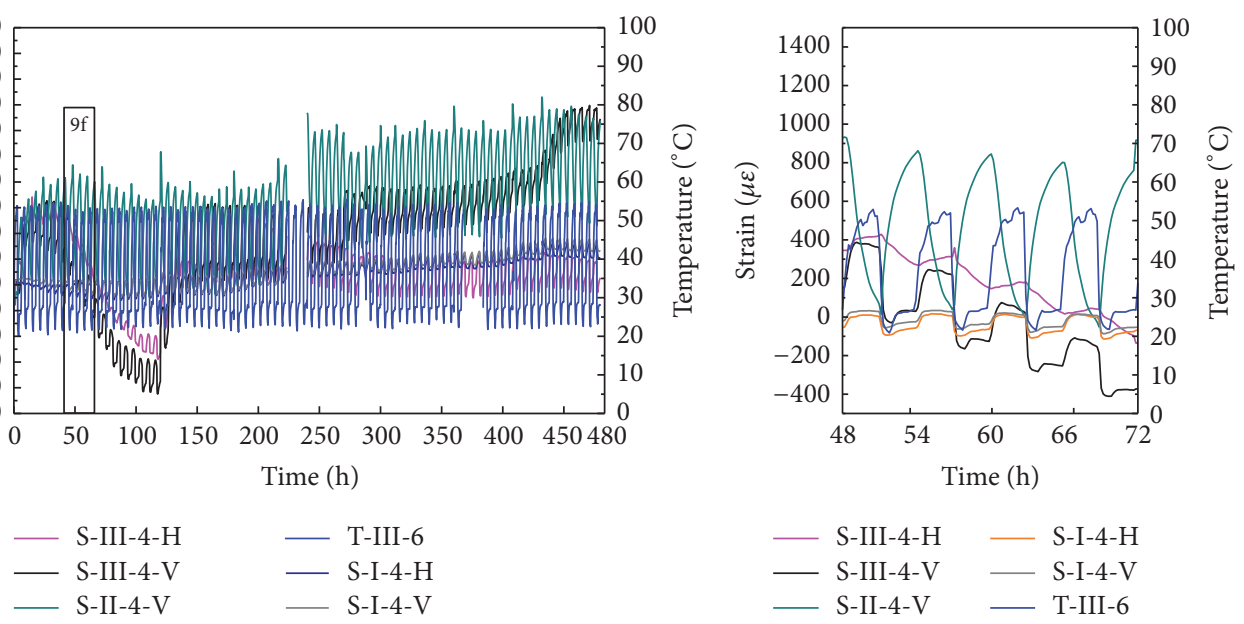

(e) In lower part

(f) Local amplifications of (e)

FIGURE 9: Strain-time-temperature relationship of three surfaces.

vertical and horizontal strains on the surface of the bonding layer are $359 /-181 \mu \varepsilon$ and $330 /-120 \mu \varepsilon$, respectively.

The different thermal deformation modes demonstrate that the hygrothermal resistance property of the bonding layer is better than that of the insulating layer. The improvement in hygrothermal resistance of the bonding layer can be explained by the influence of GHB particles. From Figure 13, it can be seen that the microstructure of GHB mortar did 


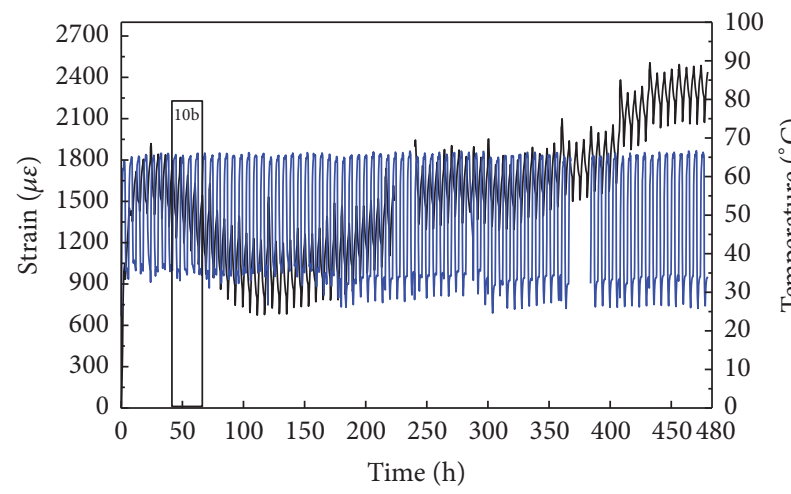

S-II-1-V

(a) In upper part

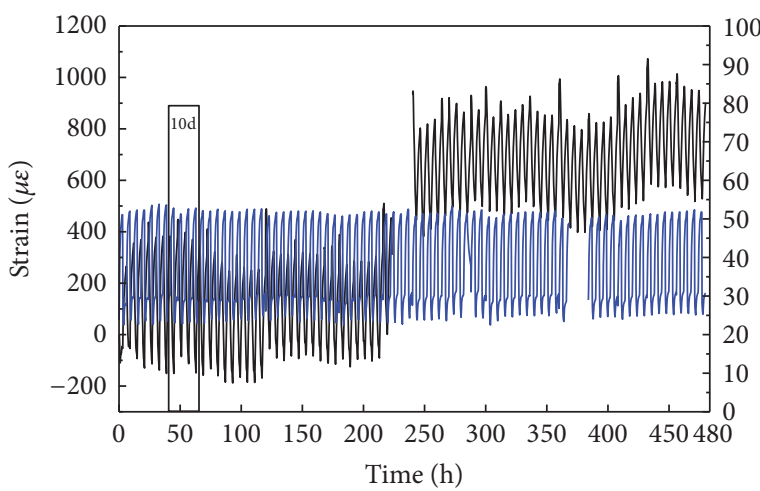

- S-II-6-H

- T-II-5

(c) In middle part

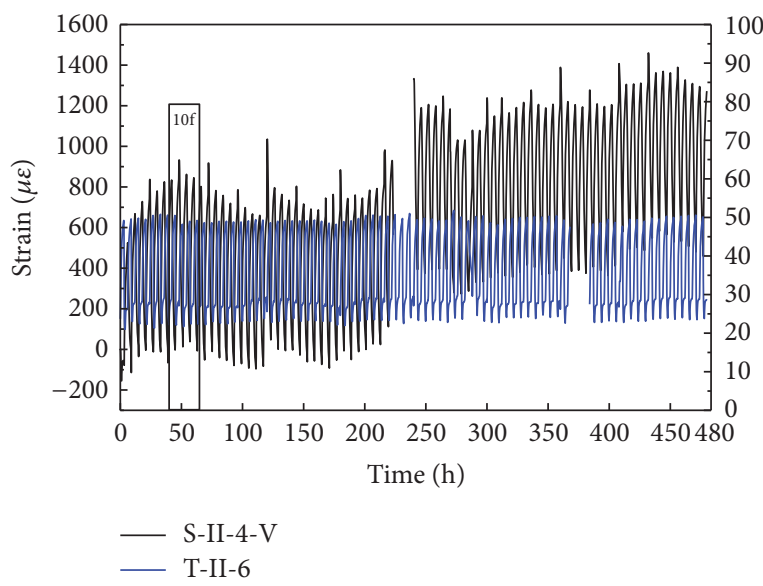

(e) In lower part

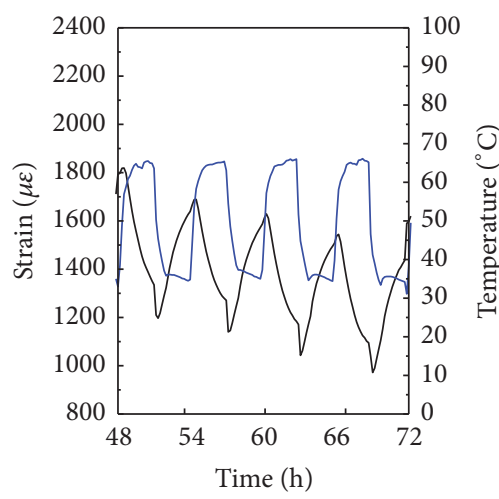

- S-II-1-V

- T-II-1

(b) Local amplifications of (a)

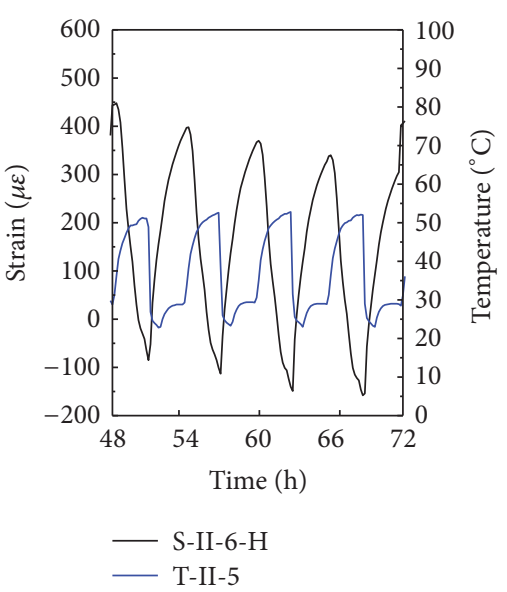

(d) Local amplifications of (c)

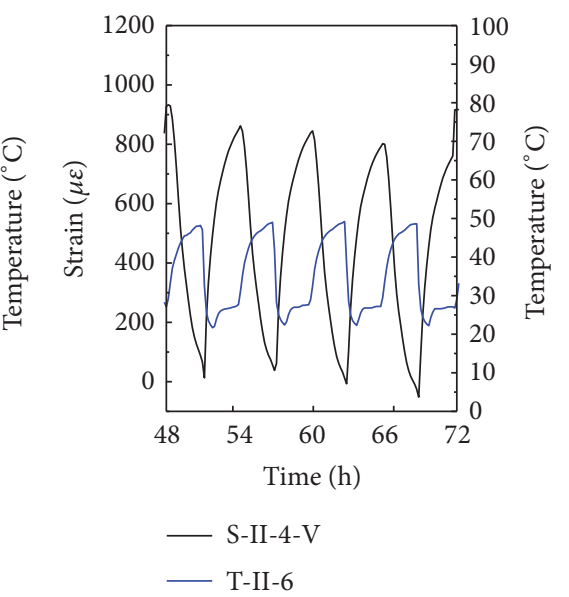

(f) Local amplifications of (e)

FIGURE 10: Strain-time-temperature relationship of insulating layer.

not change obviously under various hygrothermal cycles, the internal honeycomb pores were relatively smooth, and no significant deterioration was observed. Hence, GHB can improve hygrothermal behavior of the GHB mortar in reducing thermal deformation of the concrete substrate surface.
(3) The strain-time relationship changing curve may be divided into three stages (see Figure 14). Before the 20th hygrothermal cycle, the strain of each structural layer decreases with the increase of $N$, that is, implying the shrinkage deformation occurs (see Figure 15). The most, second to 


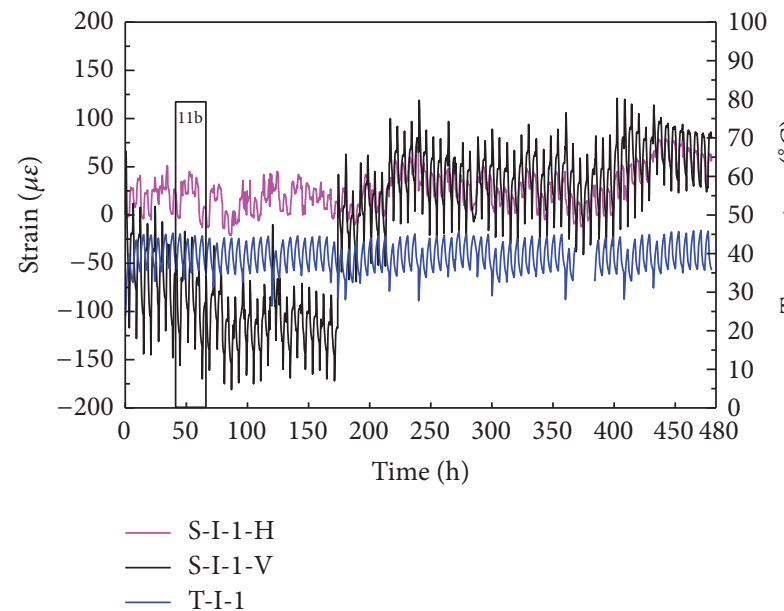

(a) In upper part
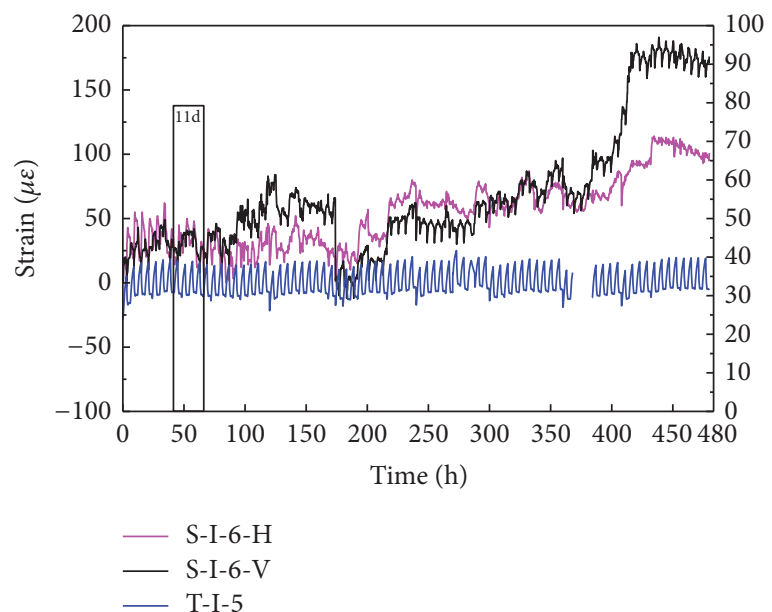

(c) In middle part

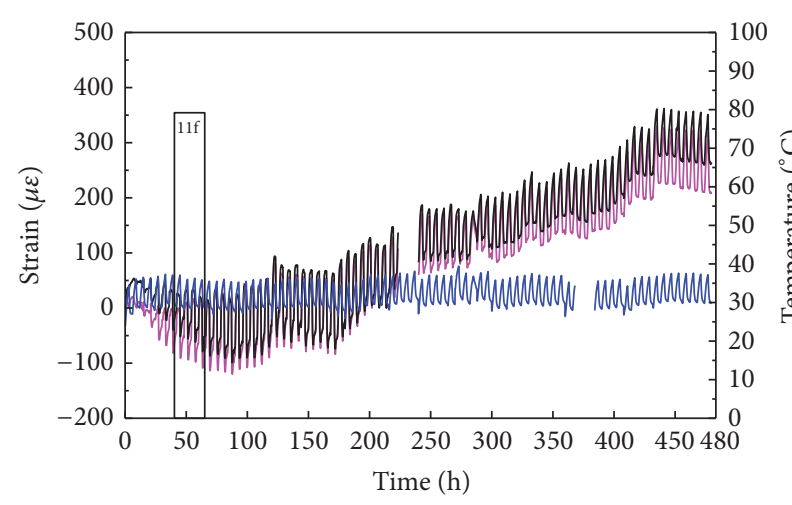

S-I-4-H

- S-I-4-V

T-I-6

(e) In lower part

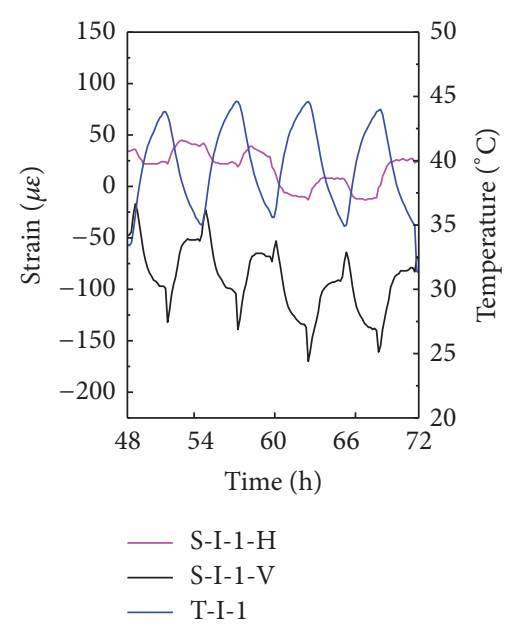

(b) Local amplifications of (a)

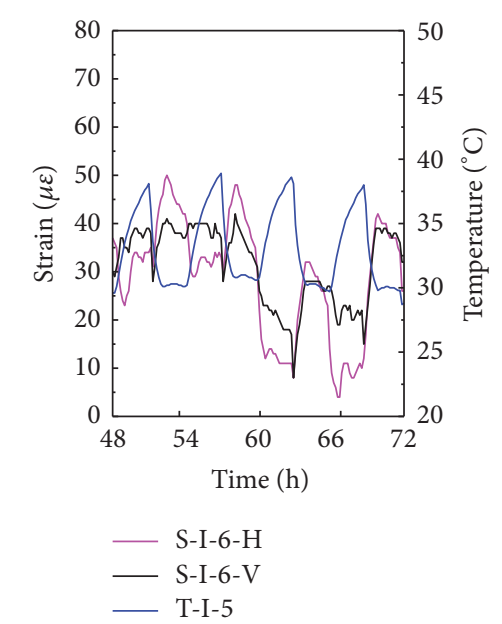

(d) Local amplifications of (c)

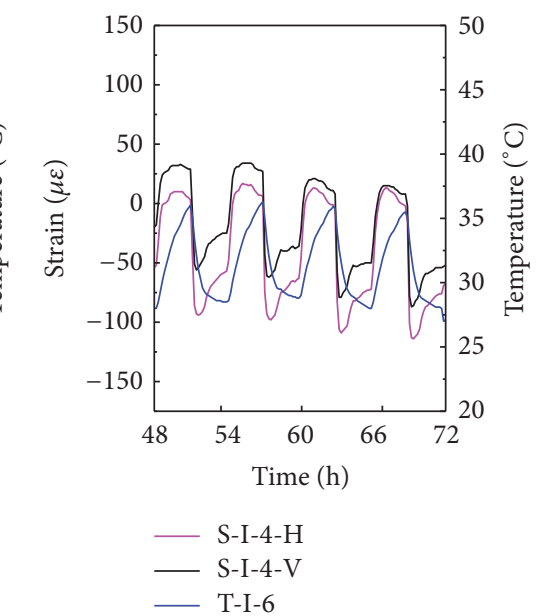

(f) Local amplifications of (e)

FIGURE 11: Strain-time-temperature relationship of bonding layer. 

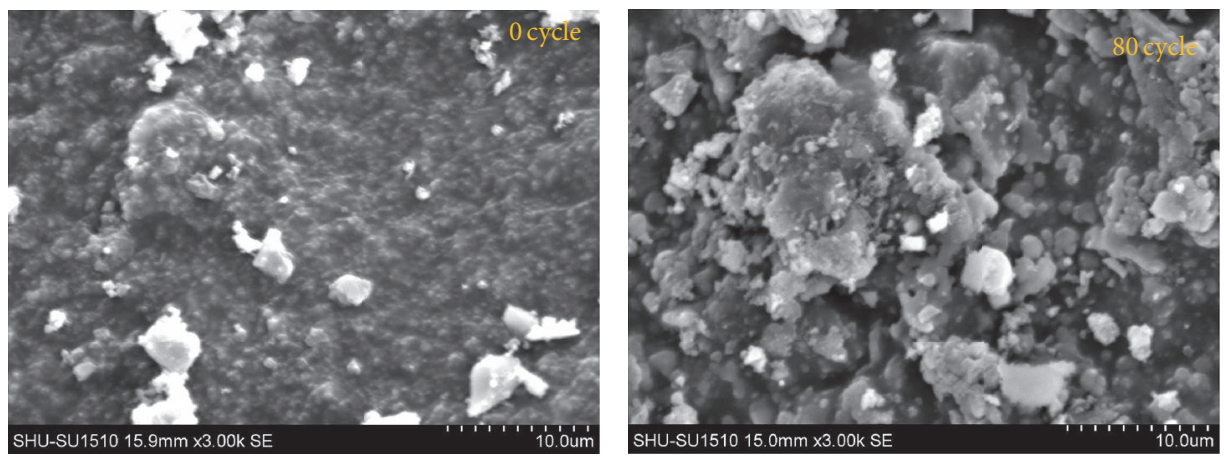

FIGURE 12: SEM graphs of top finish on the finishing coat.
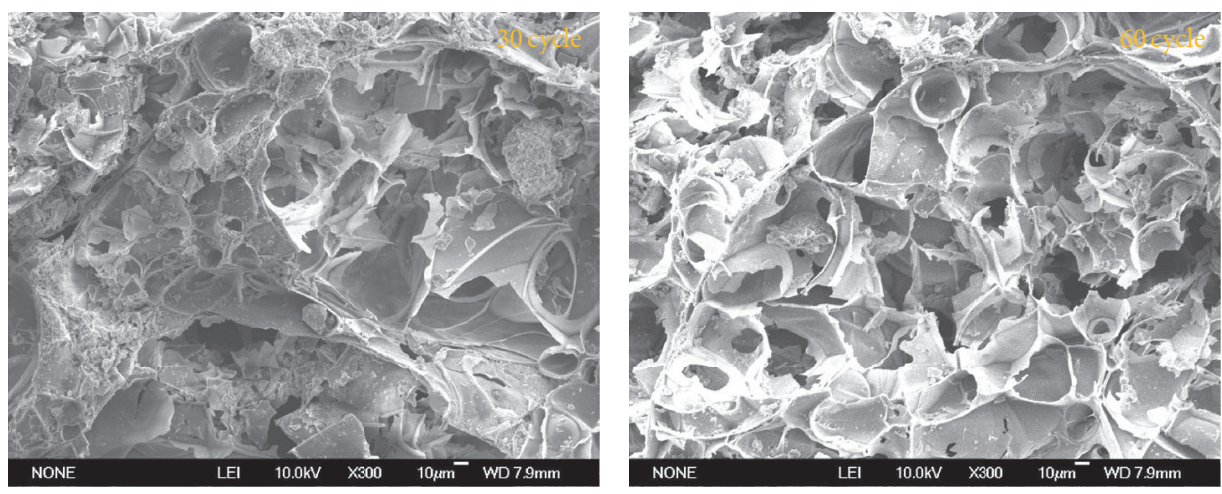

FIGURE 13: SEM graphs of GBH mortar on insulating layer.

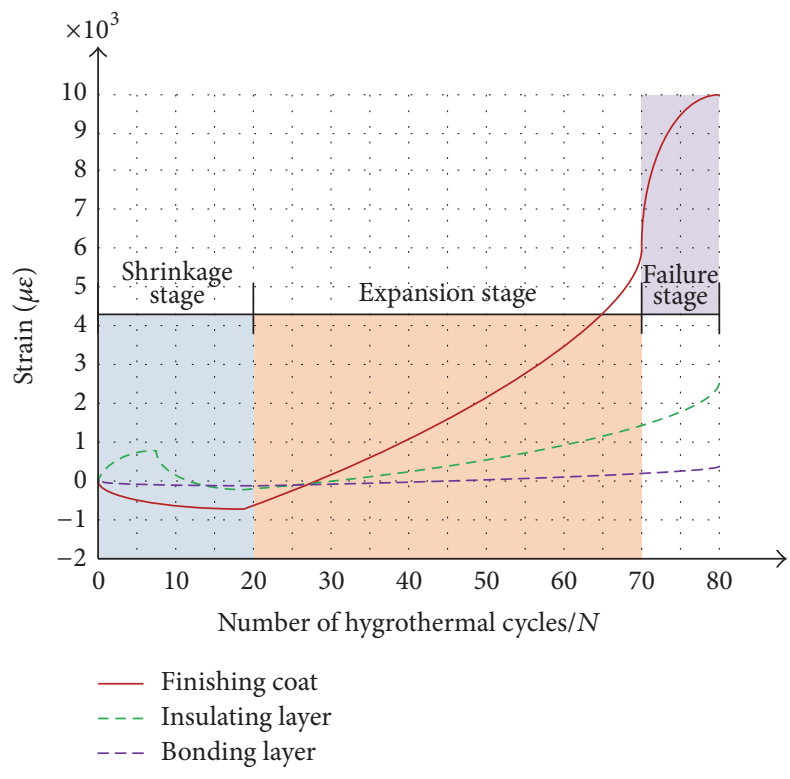

FIGURE 14: Accumulating process of fatigue damage.

most, and less significant shrinkage are located in the finishing coat, insulating layers, and bonding layers, respectively. On the whole, the deformations in the materials may be regarded at the elastic stage. At $N=70$, the changing trends in the strains of various structural layers are not similar. The horizontal strains in the finishing coat and the total strains in the insulating and bonding layers increase continuously with a relative slowly rate until the end of the test. Conversely, the vertical strains in the finishing coat increase, implying that the expansion deformation generated (see Figure 16). The tensile strain only recovers partially, especially the vertical strain of the finishing coat behaviors of the plastic deformation mode. These changing trends are consistent with those of change features in the temperature shown in Figure 7. During the last ten cycles, there is an abrupt change in the vertical strain in the finishing coat. To be specific, the changes in the strains are not significant at the upper position (Figure 9(a)) and at the lower position (Figure 9(e)) on finishing coat surface; while the strain gauge placed at middle position (see Figure 9(c)) damages, the deformation enters the failure mode.

3.3. Surface Crack. Figures 15 and 16 show the sketches of the cracks recorded by the crack width detector at $N=20$ and $N=$ 80. In these two instants, the cracks and swells on the finishing coat appeared as lines and circles. In all procedure of the test, the cracks, swells, and other degradation always occurred on the finishing coat. The rules relations between the length, width, and distribution of the cracks on the finishing coat and the number of cycles are relatively obvious. The degradation characteristics of the finishing coat from the perspectives of crack length and width will be examined as follows.

(1) On the surface of the finishing coat (see Figure 15), most of the cracks are in the horizontal direction, 

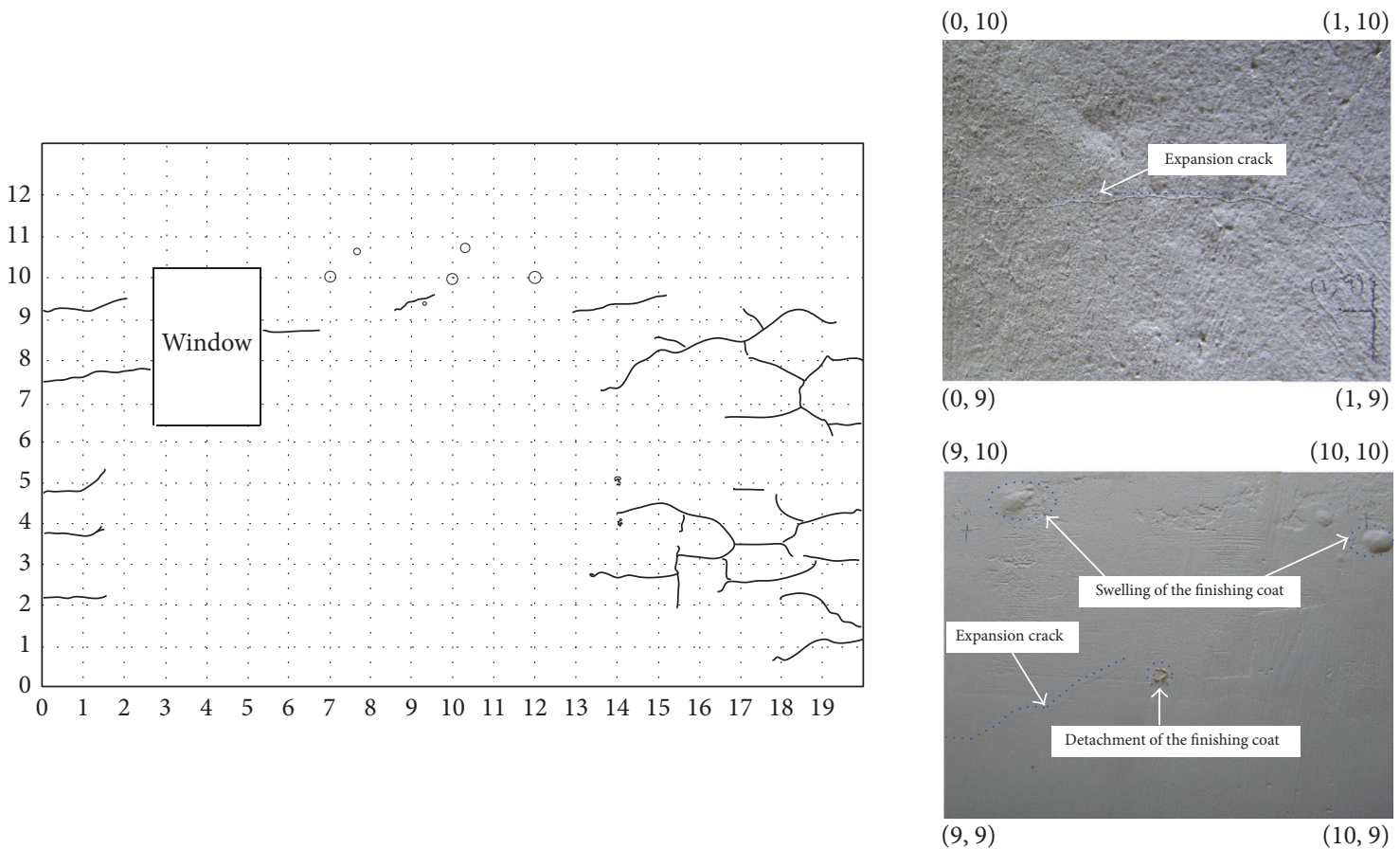

FIGURE 15: Crack propagations on the finishing coat, the 20 cycles.
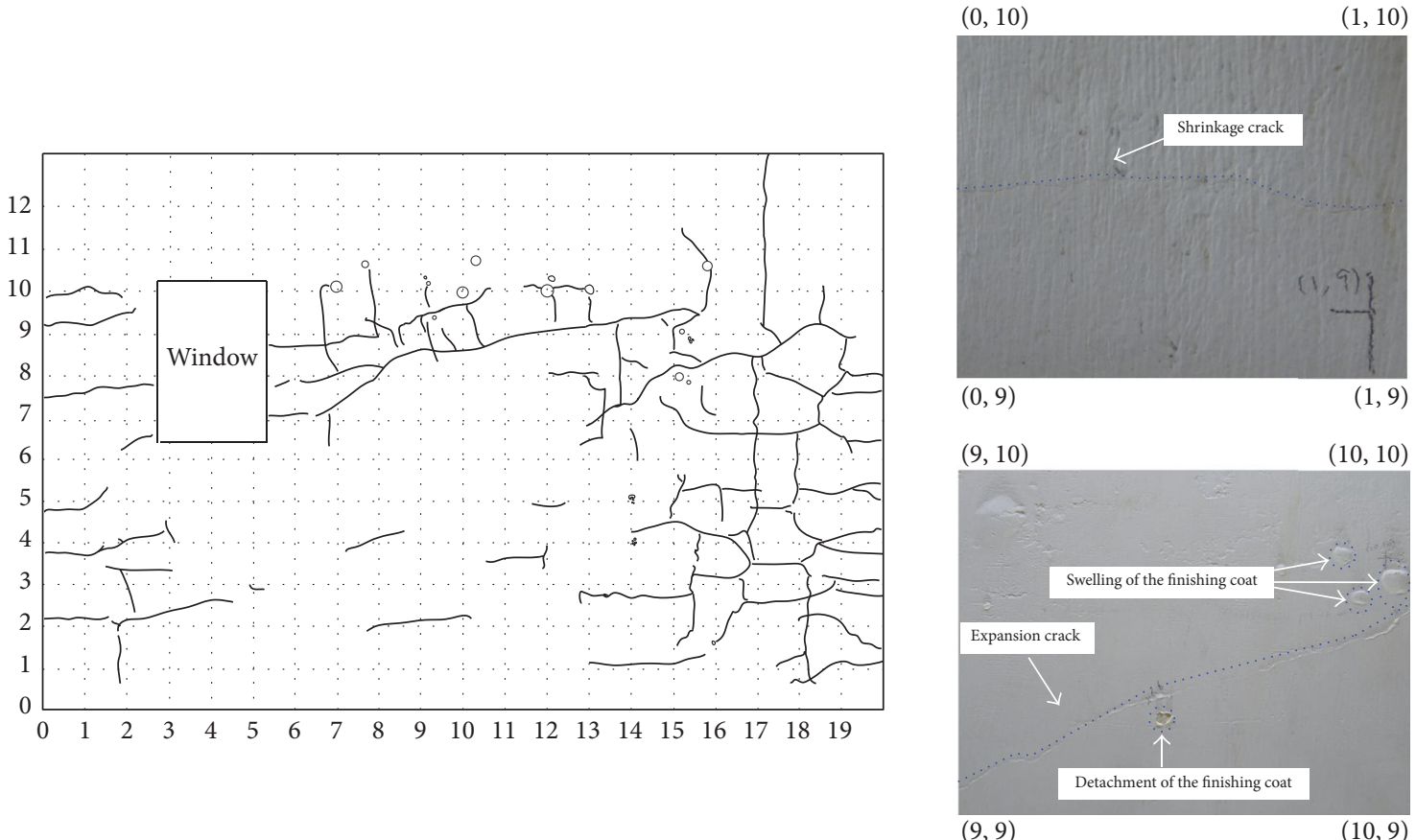

FIGURE 16: Crack propagations on the finishing coat, the 80 cycles.

the second to most of the cracks are vertical ones, and very few of the oblique cracks appeared. The reason is that the temperatures on the surface of the finishing coat in the vertical direction changed more intensely than those in other directions (see Figures 7 and 8). So, the newly generated temperature stress made it easier for cracks to emerge. As a result, under the repeated actions of the hygrothermal load, most of the cracks formed along the horizontal direction and developed relatively quickly. These cracks may converge to some extent. To be specific, the horizontal and vertical cracks converged regionally, while the oblique cracks distributed locally. The cracks on the finishing coat only initially existed on the surface 
TABLE 4: Number, length, and increase magnitude of cracks.

\begin{tabular}{|c|c|c|c|c|c|}
\hline \multirow{2}{*}{ Number of cycles/ $N$} & \multirow{2}{*}{ Number } & \multirow{2}{*}{ Total length/m } & \multicolumn{2}{|c|}{ Increase magnitude/\% } & \multirow{2}{*}{ Max. width/mm } \\
\hline & & & Number & Total length & \\
\hline 12 & 28 & 8.51 & - & - & 0.07 \\
\hline 20 & 45 & 12.13 & 61 & 43 & 0.09 \\
\hline 40 & 64 & 18.22 & 42 & 50 & 0.10 \\
\hline 60 & 80 & 22.05 & 25 & 21 & 0.12 \\
\hline 72 & 89 & 24.18 & 11 & 10 & 0.16 \\
\hline 80 & 92 & 24.68 & 3 & 2 & 0.17 \\
\hline
\end{tabular}

of the coating material but subsequently extended to the inside of the material. However, they did not penetrate the finishing coat.

(2) As shown in Table 4, the number, the length, and width of the cracks on the surface of the finishing coat gradually increase with the increase in the number of cycles. Specifically, the most significant increase is the number of cracks, followed by the total length of cracks. The increase in the width of cracks is not significant. All of these three parameters decrease with the increasing in $N$. In particular, for $N>$ 20 , the cracks on the surface of the finishing coat developed rapidly, also being verified by the strains in Figure 9(c). For $N=72$, only a few new cracks formed and stably propagated. Therefore, after 72 hygrothermal cycles, the degradation of the ETICS is not significant, suggesting that setting the number of hygrothermal cycles at 80 in ETAG 004 [26] is appropriate.

\section{Conclusions}

In this study, the temperature and strain in three various structural layers (i.e., finishing coat, insulating layer, and the bonding layer) of the ETICS GHB under the hygrothermal cycles were investigated. Based on the test results, the following conclusions were obtained:

(1) Due to the differences in the thermophysical properties, the relations between temperature distributions on the surface and inside the chamber are different for three structural layers. These differences contributed to the internal stresses in the structural layers. The temperature difference between different positions on the same plane of the finishing coat and the insulating layer is $20^{\circ} \mathrm{C}$. On the other hand, for the bonding layer, the difference is only around $5^{\circ} \mathrm{C}$. The local temperature difference existing on the surface of the finishing coat may cause the surface crack openning on the finishing coat. The temperature of the bonding layer is not excessively high because of the thermal insulation action of the insulating layer.

(2) Most of the thermal deformation on the surface of three layers is moisture expansion and dryingshrinkage one and thermal expansion one, respectively, at the early stage and at the later stage. The surface strain of the finishing coat shows three stages of deformation with the increasing of $N$ : for $N<20$, the shrinking elastic deformation occurs; for $20<$ $N<70$, the expansion-type elastoplastic deformation occurs; for $N>0$, the plastic failure deformation occurs. The change trends of the surface strains in the insulating and bonding layers with the increase of $N$ are similar, except that magnitude in the insulating layer is smaller. Due to the surface strain of the bonding layer, the elastic deformation occurs.

(3) The cracks on the surface of the finishing coat mostly converged into horizontal ones, followed by vertical cracks, and, lastly, locally formed a few of oblique cracks. With increasing $N$, the most significant increase is the number of cracks on the finishing coat and then the length of the cracks. The width of the cracks increased is gradually. However, the increase rate of these parameters (i.e., number, length, and width) decreases with the increase in $N$. The cracks of the finishing coat are the generation, expansion, and saturation modes, respectively, for $N<20,20<N<$ 70 , and $N>70$.

(4) GHB mortar with internal honeycomb pores and smooth closed surface has good water retention capacity and stable structure. Hence, the special pore structure can reduce the thermal conductivity of GHB mortar, prevent the moisture migration extension of concrete substrate, and accordingly alleviate the hygrothermal behavior of the bonding layer.

\section{Competing Interests}

The authors declare that they have no competing interests.

\section{Acknowledgments}

This work was financially supported by the National Natural Science Foundation of China (no. 41472254 and no. 51308371), Jiaxing University School-Class Key Topics of Funded Projects (no. 70115020), Jiaxing Science and Technology Project (no. 2016AY13009), and The "Twelfth Five-Year" Key Disciplines in the Universities of Zhejiang Province, Discipline of Building Energy Efficiency Technology (Department of Education of Zhejiang Province Office Document [2012] no. 80). 


\section{References}

[1] Q.-P. Pu, B.-Z. Li, and W. Yu, "Energy consumption forecast model of urban residential buildings in Chongqing," Journal of Central South University (Science and Technology), vol. 43, no. 4, pp. 1551-1556, 2012.

[2] T.-S. Gu, L.-Y. Xie, and G. Chen, "Building energy conservation and wall thermal insulation," Engineering Mechanics, vol. 23, no. 2, pp. 167-184, 2006.

[3] I. Mandilaras, I. Atsonios, G. Zannis, and M. Founti, "Thermal performance of a building envelope incorporating ETICS with vacuum insulation panels and EPS," Energy and Buildings, vol. 85, pp. 654-665, 2014.

[4] F. E. Boafo, Z. Chen, C. Li, B. Li, and T. Xu, "Structure of vacuum insulation panel in building system," Energy and Buildings, vol. 85, pp. 644-653, 2014.

[5] L. Zhao, W. Wang, Z. Li, and Y. F. Chen, "Microstructure and pore fractal dimensions of recycled thermal insulation concrete," Materials Testing, vol. 57, no. 4, pp. 349-359, 2015.

[6] X. Li and G. Li, "Effect of latex powder and glass fiber on the performance of glazed hollow bead thermal insulation materials," Journal of Building Materials, vol. 17, no. 2, pp. 314-319, 2014.

[7] J. Zhu and G. Li, "Performance of thermal insulation materials of polypropylene fiber reinforced vitrified small ball," Journal of Building Materials, vol. 18, no. 4, pp. 658-703, 2015.

[8] J.-Q. Gong and C.-T. Zhang, "Study on the thermal conductivity model of hollow beads insulating mortar," Journal of Hunan University Natural Sciences, vol. 41, no. 6, pp. 99-105, 2014.

[9] S. Fan and P. Wang, "Effect of air entraining agents on the longterm drying shrinkage of glazed hollow beads thermal insulation mortar," Journal of Building Materials, vol. 19, no. 1, pp. 1-7, 2016.

[10] P. Ren, X.-H. Li, and Q.-L. Meng, "Thermal and moisture performance of insulation glazed hollow bead motar," Journal of Civil Architectural \& Environmental Engineering, vol. 32, no. 4, pp. 71-75, 2010.

[11] Q.-T. Yu, P. Pan, and Y.-K. Su, "Experimental study on seismic behavior of light-gauge steel wall filled with glazed hollow bead mortar," Engineering Mechanics, vol. 32, no. 3, pp. 151-157, 2015.

[12] W. Wang, L. Zhao, Y. Liu, and Z. Li, "Mechanical properties and stress-strain relationship in axial compression for concrete with added glazed hollow beads and construction waste," Construction and Building Materials, vol. 71, no. 11, pp. 425-434, 2014.

[13] Y. Liu, Y. F. Chen, W. Wang, and Z. Li, "Bond performance of thermal insulation concrete under freeze-thaw cycles," Construction and Building Materials, vol. 104, no. 2, pp. 116-125, 2016.

[14] H. Shen, H. Tan, and A. Tzempelikos, "The effect of reflective coatings on building surface temperatures, indoor environment and energy consumption-an experimental study," Energy and Buildings, vol. 43, no. 2-3, pp. 573-580, 2011.

[15] S. Ximenes, J. de Brito, P. L. Gaspar, and A. Silva, "Modelling the degradation and service life of ETICS in external walls," Materials and Structures, vol. 48, no. 7, pp. 2235-2249, 2015.

[16] B. Amaro, D. Saraiva, J. De Brito, and I. Flores-Colen, "Inspection and diagnosis system of ETICS on walls," Construction and Building Materials, vol. 47, pp. 1257-1267, 2013.

[17] B. Daniotti, F. R. Cecconi, R. Paolini, R. Galliano, J. Ferrer, and L. Battaglia, "Durability evaluation of ETICS: analysis of failures case studies and heat and moisture transfer simulations to assess the frequency of critical events," in Proceedings of the 4th Portuguese Conference on Mortars and ETICS, Coimbra, Portugal, 2012, http://www.apfac.pt/congresso2012/comunicacoes/Paper\%20104_2012.pdf.

[18] D. Zirkelbach, A. Holm, and H. M. Künzel, "Influence of temperature and relative humidity on the durability of mineral wool in ETICS," in Proceedings of the 10DBMC International Conference on Durability of Building Materials and Components, Lyon, France, April 2005.

[19] J. Zhang, Y. Gao, and Z. Huang, "Comparative studies on the temperature stresses in external walls with different thermal insulation models," Journal of Harbin Engineering University, vol. 32, no. 7, pp. 895-905, 2011.

[20] A. Collina and G. P. Lignola, "The External Thermal Insulation Composite System (ETICS) more than comfort and energy saving," in Proceedings of the 3rd Portuguese Congress on Construction Mortars, Lisbon, Portugal, 2010 (Portuguese).

[21] C. Balocco, G. Grazzini, and A. Cavalera, "Transient analysis of an external building cladding," Energy and Buildings, vol. 40, no. 7, pp. 1273-1277, 2008.

[22] D. S. Passa, A. B. Sotiropoulou, Z. G. Pandermarakis, and G. D. Mitsopoulos, "Thermal and drying cyclic loading for cement based mortars and expanded polystyrene foam layers," Applied Mechanics and Materials, vol. 204-208, pp. 3648-3651, 2012.

[23] C. Y. Yiu, D. C. W. Ho, and S. M. Lo, "Weathering effects on external wall tiling systems," Construction and Building Materials, vol. 21, no. 3, pp. 594-600, 2007.

[24] G. Griciute and R. Bliudzius, "Study on the microstructure and water absorption changes of exterior thin-layer polymer renders during natural and artificial ageing," Materials Science, vol. 21, no. 1, pp. 149-154, 2015.

[25] B. Daniotti, R. Paolini, and F. R. Cecconi, "Effects of ageing and moisture on thermal performance of ETICS cladding," in Durability of Building Materials and Components, vol. 3 of Building Pathology and Rehabilitation, pp. 127-171, Springer, Berlin, Germany, 2013.

[26] ETAG 004, Guideline for European technical approval of External thermal insulation composite systems with rendering, European Organisation for Technical Approvals, March 2000. 

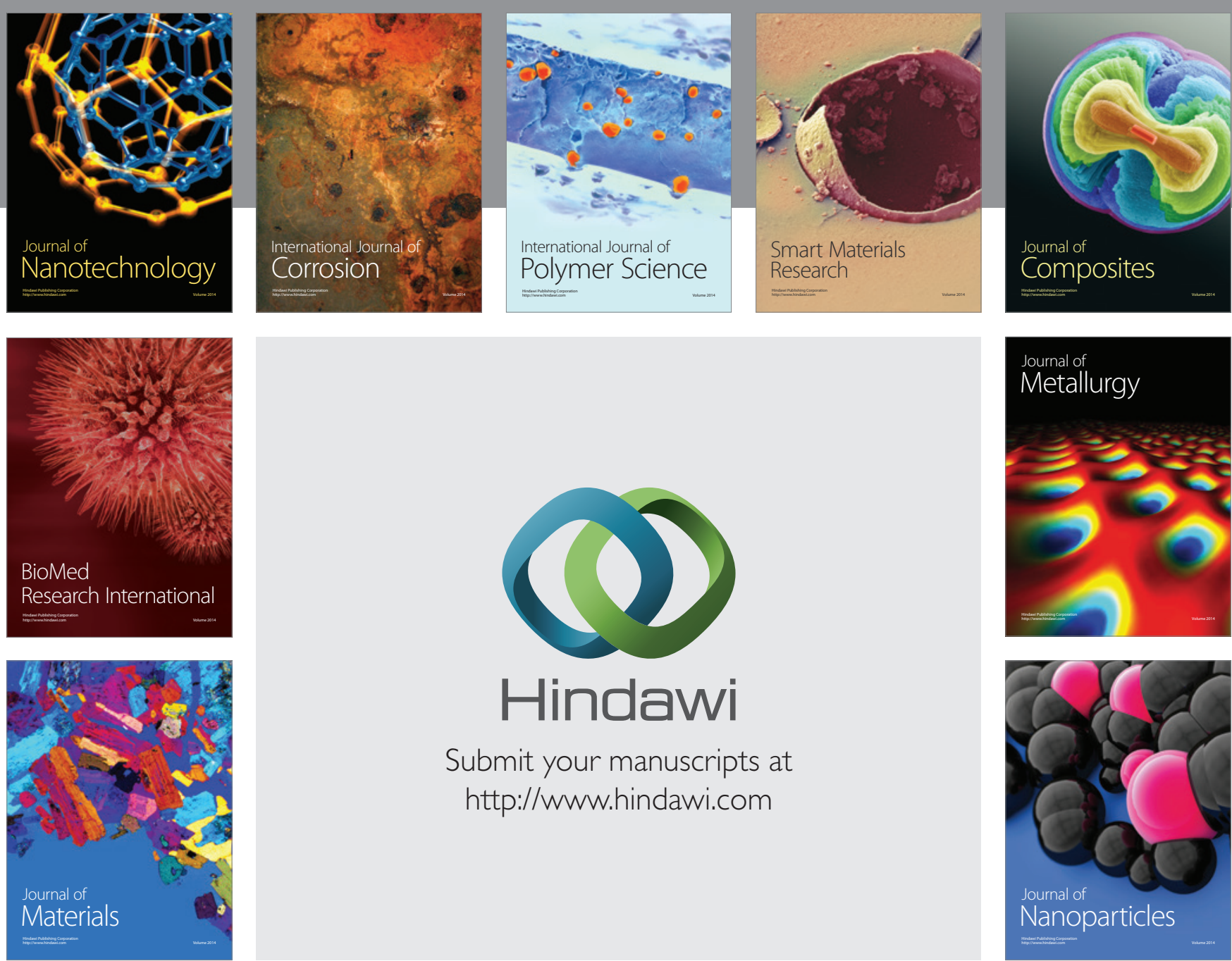

\section{Hindawi}

Submit your manuscripts at

http://www.hindawi.com

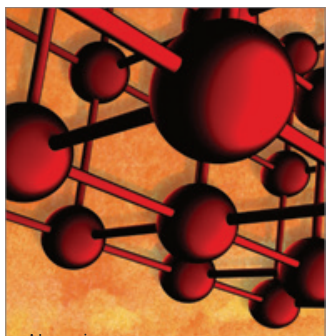

Materials Science and Engineering
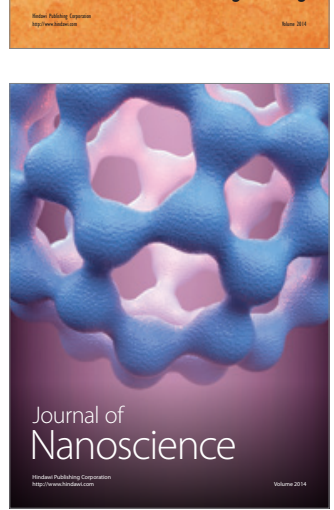
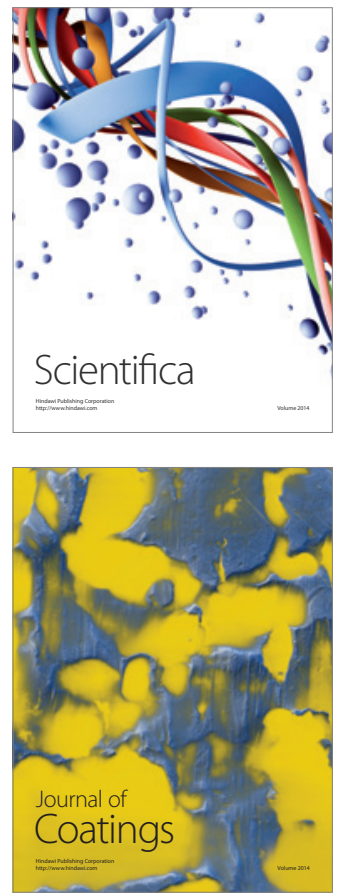
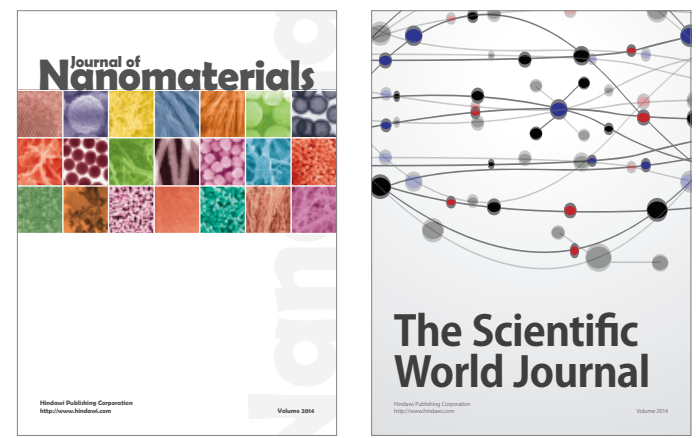

The Scientific World Journal
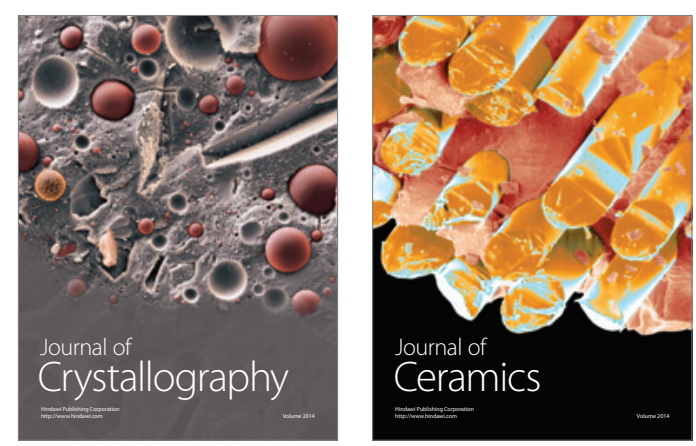
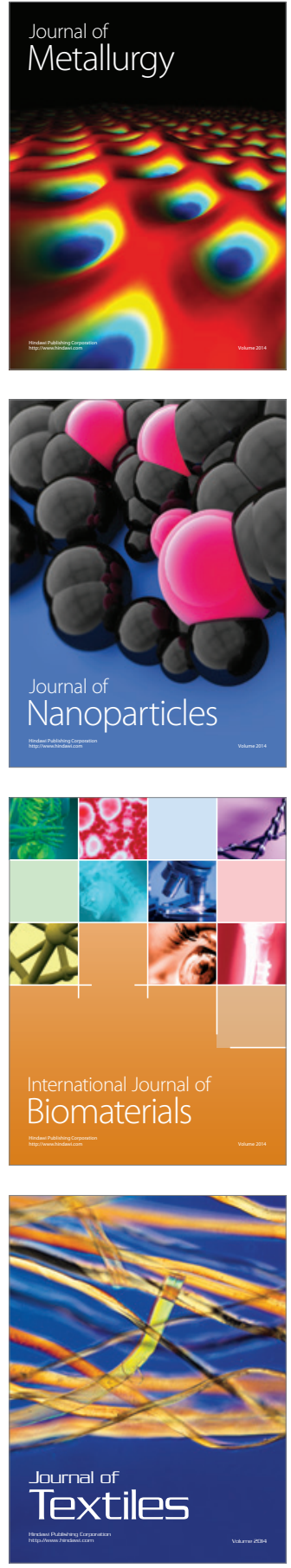